\title{
Long-term cost-utility analysis of remote monitoring of older patients with pacemakers: the PONIENTE study
}

\author{
Rafael Jesus Bautista-Mesa', Antonio Lopez-Villegas ${ }^{2 *}$, Salvador Peiro ${ }^{3}$, Daniel Catalan-Matamoros ${ }^{4,5}$ \\ Emilio Robles-Musso ${ }^{6}$, Remedios Lopez-Liria ${ }^{7}$ and Cesar Leal-Costa ${ }^{8}$
}

\begin{abstract}
Background: Cost-effectiveness studies on pacemakers have increased in the last years. However the number of long-term cost-utility studies is limited. The objective of this study was to perform a cost-utility analysis comparing remote monitoring (RM) versus conventional monitoring (CM) in hospital of older patients with pacemakers, 5 years after implant.

Methods: Under a controlled, not randomized, nor masked clinical trial, 83 patients with pacemakers were initially selected. After five years of follow-up, a total of 55 patients $(C M=34 ; R M=21)$ completed the study. A cost-utility analysis of RM in terms of costs per gained quality-adjusted life years (QALYS) was conducted. The costs from the Public Health System (PHS) as well as patients and their relatives were taken into account for the study. The robustness of the results was verified by the probabilistic analyses through Monte-Carlo simulations.
\end{abstract}

Results: After a five-year follow-up period, total costs were lower in the RM group by 23.02\% than in the CM group $(€ 274.52$ versus $€ 356.62 ; p=0.033)$ because of a cost saving from patients' perspective $(€ 59.05$ versus $€ 102.98 ; p=$ 0.002). However, the reduction of in-hospital visits derived from RM exhibited insignificant impact on the costs from the PHS perspective, with a cost saving of $15.04 \%$ ( $€ 215.48$ vs. $€ 253.64 ; p=0.144)$. Costs/QALYs obtained by the RM group were higher as compared to the CM group, although there were no significant differences. The incremental cost-effectiveness ratio of CM in comparison to RM became positive (€301.16).

Conclusions: This study confirms RM of older patients with pacemakers appears still as a cost-utility alternative to CM in hospital after 5 years of follow-up.

Trial registration: ClinicalTrials.gov: (Identifier: NCT02234245). Registered 09 September 2014 - Prospectively registered.

Keywords: Cost-utility, Pacemakers follow-up, Quality-adjusted life years, Remote monitoring, Telemedicine

\footnotetext{
* Correspondence: antoniolopezvillegas@andaluciajunta.es

${ }^{2}$ Social Involvement of Critical and Emergency Medicine, CTS-609 Research

Group, Hospital de Poniente, El Ejido, s/n, 04700 Almeria, Spain

Full list of author information is available at the end of the article
}

(c) The Author(s). 2020 Open Access This article is licensed under a Creative Commons Attribution 4.0 International License, which permits use, sharing, adaptation, distribution and reproduction in any medium or format, as long as you give appropriate credit to the original author(s) and the source, provide a link to the Creative Commons licence, and indicate if changes were made. The images or other third party material in this article are included in the article's Creative Commons licence, unless indicated otherwise in a credit line to the material. If material is not included in the article's Creative Commons licence and your intended use is not permitted by statutory regulation or exceeds the permitted use, you will need to obtain permission directly from the copyright holder. To view a copy of this licence, visit http://creativecommons.org/licenses/by/4.0/. The Creative Commons Public Domain Dedication waiver (http://creativecommons.org/publicdomain/zero/1.0/) applies to the data made available in this article, unless otherwise stated in a credit line to the data. 


\section{Background}

As per the norms of the professional practice guidelines, revisions at a frequency of every 3-12 months are essential for older patients implanted with pacemakers (PM) to evaluate the patient's clinical status as well as the PM functioning and, in case, its reprogrammation $[1,2]$. Remote monitoring (RM), an alternative to conventional monitoring $(\mathrm{CM})$ appeared two decades ago $[1,3,4]$ in hospitals. It was implemented to balance time and costs requirements not only from the Public Health System (PHS) [5] perspective but also from patients and their relatives' perspective $[4,6]$.

Existing research has demonstrated RM as effective as hospital monitoring [1, 6-9], in terms of safety [3] and reduction of the time to clinical decision and intervention. It provides rapid detection of cardiovascular events [10] or device malfunction as well as reduces inappropriate shocks and spares implantable cardioverter defibrillators' batteries [9, 11]. RM is also successful in improving patient's satisfaction and gaining their confidence. RM empowers patients for self-management of their conditions $[12,13]$. Visits to the hospitals become limited only for relevant device alerts [10,14]. The number of unscheduled in-hospital visits, the assistance of emergency services, and hospitalizations are reduced by RM $[5,15]$. On the contrary, it is essential to educate and train the patients properly regarding the purpose and benefits of RM, its usage, and limitations [16] so that their preferences for in-hospital follow-up could be reduced [17]. This is related to social acceptance of telehealth, one of the three dimensions jointly utility and usability that would help predict how a new technology will be utilized with patients $[18,19]$.

Cost-effectiveness analyses are employed to compare the effectiveness of new interventions against their incremental cost to be considered in the medical decisionmaking process as well as in public policy $[14,20]$. The last few years have witnessed an upsurge in the number of cost-effectiveness studies on cardiovascular implantable electronic devices [8, 9, 21-25]. However, there have been only a few studies that analyzed cost-utility in terms of quantity and health-related quality of life (HRQL) of older patients, especially in the long-term $[5,10,14,26-29]$.

Early results from the cost-utility analysis performed in the PONIENTE study after a 12-months follow-up period [30], confirmed that RM of patients with PMs is a cost-saving and cost-utility alternative in comparison to conventional follow-up in a hospital. This article is an extension of the PONIENTE study to a five-year followup period, with the aim of evaluating cost-utility (in terms of cost per quality-adjusted life-years gained, (QALYs) of long-term RM of older patients with pacemakers.

\section{Methods}

The PONIENTE study is a controlled, neither randomized nor masked, single-center clinical trial, designed to compare RM of older patients with pacemakers (active group) to the CM in hospital (control group), with 5 years of follow-up from the initial date of pacemakers implantation (between October 2012 to November 2013).

\section{Intervention description}

The PONIENTE trial was conducted on older patients (81 years old on average) recruited in the Poniente Hospital (Almeria-Spain) implanted with commercially available pacemakers equipped with the Medtronic CareLink $^{\circ}$ Network. As previously reported [7, 30], 83 patients were initially included in the cost-utility study. Other relevant information about the PM technology, as well as its functioning mode, was mentioned in a previous paper [31]. Effectiveness results (functional capacity, event detection, and workload) were also depicted in an earlier paper [7]. Based on the study protocol, patients were followed-up for a period of 5 years after the implant date through scheduled in-hospital visits or remote monitoring. One month after the implant date, the physician scheduled an in-office visit with the patients, explained the characteristics of both types of monitoring and tried to determine which type of monitoring (remote or conventional) was better suited to the patient characteristics. Patients included in both groups were managed according to the usual practices of the hospital, abiding by the international guidelines with follow-up visits scheduled under physician's criteria and regulation from the Spanish Health Authority. The number of visits to the hospital $(\mathrm{CM}=7.49$ and $\mathrm{RM}=4.38$ on average in the total 5-years of follow up period) and/or transmissions from home ( $R M=6.62$ on average in the total 5years of follow up period) for each patient and year depended on the type of pacemaker implanted and patient characteristics.

Patients who opted for the RM were provided with a device (Medtronic Carelink Home Monitor) for data transmissions through a standard phone line from home to a central database, where data were processed and made accessible to physicians and healthcare team. It does not provide any additional therapeutic capabilities to the devices. The corresponding PM parameters were programmed, the use of the device as well as the protocol for sending data was explained and, finally, the service from the supplier company was requested by the physicians. Following the norms of the international consensus on the monitoring of cardiovascular implantable electronic devices [1], PM specifications, and physicians' criteria, patients under RM were asked to submit data at different time points. No further in-hospital visits 
were scheduled for patients in the RM group. On the contrary, they were connected over the telephone and referred for an in-office visit, if data transmissions detected any device dysfunction or cardiovascular event. Data collected from all remote transmissions were scrutinized daily by the administrative staff and reviewed by the physicians through password-protected remote access.

\section{Costs analysis}

Costs analysis was studied from two different perspectives (Table 1): firstly, costs incurred by the hospital, funded by the Spanish PHS; secondly, social costs afforded by the patients and their caregivers.

From the PHS perspective, according to the labor agreement of Poniente Hospital, labor costs were divided taking into consideration the two staff categories, physicians and administrative staffs, involved in the study. Only direct electricity supply costs were included as the consultation-room costs; other indirect costs were ignored. As previous research [28], ambulance direct costs were also taken into consideration. Pacemaker recipient costs were divided equally for both the groups. The costs for the Medtronic CareLink ${ }^{\circ}$ Network (RM group) were contributed by Medtronic $\odot$ and thus free for the PHS and patients.

Transportation costs (taxi [32], bus [33] or private transport [34]), as well as the employment income loss for the time spent by patients and (in case) caregivers in every consultation visit [35], were considered from the patient's perspective.

\section{Cost-utility analysis}

The model compares intervention costs to clinical outcomes for each patient in terms of QALYs. QALY is a generic measure of disease burden, including both the quality and the quantity of life lived, used to assess the value of medical interventions. One QALY equates to 1 year in perfect health. In our study, the QALYs values were calculated by aggregating the utility scores of the EuroQol-5D (EQ-5D) Spanish validated version [36, 37] submitted by each patient at the end of the twelfth month (by 1 year) and fifth year (by 4 years), after applying the selected discount rate. However, due to temporary comparative reasons, the utility scores collected at the implantation date and after 6 months were ignored in this study. The health-related quality of life (HRQoL) in terms of utilities was measured by EQ-5D (from - 1 [the poorest imaginable health state] to 1 [perfect health]). The cost-utility ratio was evaluated by comparing differential QALYs and differential costs between $\mathrm{CM}$ and RM groups, after 5 years. The incremental costeffectiveness ratio (ICER) was determined by calculating costs per QALYs gained for RM as compared to the CM group in the present study. According to the recommendations of the US Panel on Cost-Effectiveness in Health and Medicine [38, 39], future costs and QALYs were discounted by $3 \%$.

\section{Primary model robustness analysis}

The robustness of base-case results was evaluated by conducting a probabilistic sensitivity analysis (PSA) using Monte-Carlo simulation with 5000 iterations per group, as shown by existing research [40]. In PSA,

Table 1 Variables definition and costs included in the study

\begin{tabular}{|c|c|c|c|c|}
\hline Perspective & Variables & Unitary cost (UC) & Monitoring $^{c}$ & Cost per patient model $^{d}$ \\
\hline \multirow[t]{8}{*}{$\overline{P u b l i c ~ H e a l t h ~ S y s t e m ~}^{a}$} & \multirow[t]{2}{*}{ Physician labor costs } & \multirow[t]{2}{*}{$€ 0.54 / \mathrm{min}$} & CM & $\mathrm{NVH} \times \mathrm{PTH} \times \mathrm{UC}$ \\
\hline & & & RM & NRT $\times$ PTR $\times$ UC \\
\hline & \multirow[t]{2}{*}{ Administrative labor costs } & \multirow[t]{2}{*}{$€ 0.27 / \mathrm{min}$} & CM & $\mathrm{NVH} \times \mathrm{ATH} \times \mathrm{UC}$ \\
\hline & & & RM & NTH $\times$ ATR $\times$ UC \\
\hline & \multirow[t]{2}{*}{ Consultation-room } & \multirow[t]{2}{*}{$€ 0.029 / \mathrm{min}$} & CM & \multirow[t]{2}{*}{$\mathrm{NVH} \times \mathrm{PTH} \times \mathrm{UC}$} \\
\hline & & & RM & \\
\hline & \multirow[t]{2}{*}{ Ambulance } & \multirow[t]{2}{*}{$€ 1.13 / \mathrm{km}$} & CM & \multirow[t]{2}{*}{$\mathrm{NVHA} \times \mathrm{UC}$} \\
\hline & & & RM & \\
\hline \multirow[t]{4}{*}{ Patients and relatives ${ }^{\mathrm{b}}$} & \multirow[t]{2}{*}{ Transportation (round trip) } & \multirow{2}{*}{$\begin{array}{l}\text { Taxi (ranged from } € 14.50 \text { to } € 142.10 \text { ); } \\
\text { Bus (ranged from } € 2.60 \text { to } € 7.43 \text { ); } \\
\text { Private car ( } € 0.19 / \mathrm{km})\end{array}$} & $C M$ & \multirow[t]{2}{*}{$(\mathrm{NVH}-\mathrm{NVHA}) \times$ UCIT } \\
\hline & & & $\mathrm{RM}$ & \\
\hline & \multirow[t]{2}{*}{ Lost income costs for hospital visits [20] } & \multirow[t]{2}{*}{$€ 5.05 / \mathrm{h}$ of home help service } & CM & \multirow[t]{2}{*}{$\mathrm{NVH} \times \mathrm{TVH} \times \mathrm{UC}$} \\
\hline & & & RM & \\
\hline
\end{tabular}

\footnotetext{
${ }^{a}$ Cost information was provided by the Cost Accounting Unit of Poniente Hospital

${ }^{b}$ Data collected through questionnaires by participants in every visit to Poniente Hospital

c $\mathrm{CM}=$ Conventional Monitoring; RM = Remote Monitoring

${ }^{\mathrm{d}}$ NVH number of visits to hospital; PTH time by physician per visit at hospital; UC unitary cost; NRT number of remote transfers to hospital; PTR time by physician per remote transfer; ATH time by administrative staff per visit at hospital; ATR time by administrative staff per remote transfer; NVHA number of visits to hospital by ambulance; UCIT unitary cost of informal transport; TVH unitary time spent by visit to hospital
} 
Table 2 Estimation of stochastic variables for Probabilistic Sensitivity Analysis

\begin{tabular}{|c|c|c|c|c|c|c|c|c|}
\hline \multirow[t]{2}{*}{ Variable $^{a}$} & \multirow[t]{2}{*}{ Monitoring } & \multicolumn{3}{|c|}{$\begin{array}{l}\text { Intervention groups } \\
{[\mathrm{n}(\mathrm{CM})=34 ; \mathrm{n}(\mathrm{RM})=21]}\end{array}$} & \multicolumn{3}{|c|}{$\begin{array}{l}\text { Monte-Carlo simulation } \\
{[n(C M)=5000 ; n(R M)=5000]}\end{array}$} & \multirow[t]{2}{*}{$\begin{array}{l}\text { Assumed } \\
\text { distribution }\end{array}$} \\
\hline & & Mean & Std.Dev. & Interval & Mean & Std.Dev. & Interval & \\
\hline \multirow[t]{2}{*}{ NVH } & $\mathrm{CM}$ & 7.49 & 1.70 & $(4-12)$ & 9.40 & 7.24 & $(2-88)$ & Gamma \\
\hline & RM & 4.38 & 2.62 & $(2-10)$ & 6.38 & 37.34 & $(2-30)$ & Gamma \\
\hline \multirow[t]{2}{*}{ NRT } & $\mathrm{CM}$ & . & . & . & . & . & . & . \\
\hline & $\mathrm{RM}$ & 6.62 & 1.72 & $(4-9)$ & 8.64 & 6.41 & $(2-48)$ & Gamma \\
\hline \multirow[t]{2}{*}{ NVHA } & CM & 1.91 & 0.70 & $(1-3)$ & 1.90 & 1.80 & $(0-16)$ & Gamma \\
\hline & RM & 1.33 & 0.66 & $(0-3)$ & 1.31 & 1.24 & $(0-10)$ & Gamma \\
\hline \multirow[t]{2}{*}{ UCIT } & $\mathrm{CM}$ & 8.72 & 9.31 & $(2.7-40.27)$ & 8.69 & 3.18 & $(1.28-22.88)$ & Gamma \\
\hline & RM & 7.57 & 7.71 & $(2.7-34.56)$ & 7.58 & 1.44 & (3.55-13.36) & Gamma \\
\hline \multirow[t]{2}{*}{ TVH } & CM & 75.43 & 39.43 & (0-180) & 74.80 & 63.83 & $(0.33-495.32)$ & Gamma \\
\hline & RM & 88.57 & 44.98 & $(0-180)$ & 88.56 & 76.33 & $(0.04-645.03)$ & Gamma \\
\hline \multirow[t]{2}{*}{ EQ-5D M12 } & CM & 0.82 & 0.37 & $(-0.654-1)$ & 0.81 & 0.73 & $(0-6.59)$ & Gamma \\
\hline & RM & 0.90 & 0.19 & $(0.362-1)$ & 0.93 & 0.90 & $(0-7.65)$ & Gamma \\
\hline \multirow[t]{2}{*}{ EQ-5D M60 } & $C M$ & 0.77 & 0.36 & $(-0.572-1)$ & 0.75 & 0.66 & $(0-5.62)$ & Gamma \\
\hline & RM & 0.68 & 0.39 & $(-0.33-1)$ & 0.69 & 0.55 & $(0-4.28)$ & Gamma \\
\hline
\end{tabular}

${ }^{a}$ CM Conventional Monitoring; RM Remote Monitoring; NVH number of visits to hospital; NRT number of remote transfers to hospital; $N V H A$ number of visits to hospital by ambulance; UCIT unitary cost of informal transport; $T V H$ unitary time spent by a visit to hospital; EQ-5D M12 EuroQoL five-dimensional questionnaire after 12 months; EQ-5D M60 EuroQoL five-dimensional questionnaire after 5 years

uncertainty was evaluated by simultaneously varying stochastic variables in the Cost-per-patient model (Table 1) through random sampling from their assumed distributions (Table 2).

\section{Statistical analysis}

Statistical analysis was conducted using SPSS (Statistical Package for Social Sciences) statistical software v.18.0.0 (SPSS Institute, Inc., Chicago, IL, USA). Differences between groups were compared using Mann-Whitney U- test for continuous independent and non-normally distributed variables. Results were presented, including the corresponding 95\% confidence intervals (95\% CI). Logistic regression was used to assess the influence of age, sex, and the method of monitoring attrition.

\section{Results}

Patient baseline characteristics

After the five-year follow-up period, 55 patients finished the PONIENTE trial (CM: 34; RM: 21) with a mean age

Table 3 Patients' characteristics

\begin{tabular}{|c|c|c|c|c|}
\hline & All & RM group $(n=21)$ & CM group $(n=34)$ & $p$-value \\
\hline Age (mean) $\pm S D$ & $81.00 \pm 6.47$ & $81.14 \pm 7.30$ & $80.91 \pm 6.01$ & 0.690 \\
\hline Women (\%) & $17(30.91)$ & $8(38.10)$ & $9(26.47)$ & 0.365 \\
\hline Attrition $\left({ }^{a}\right)$ & $28(34.14)$ & $9(27.58)$ & $18(33.96)$ & 0.481 \\
\hline \multicolumn{5}{|l|}{ Pacing indication $(\%)(+)$} \\
\hline Sinus node disease & $11(20.00)$ & $3(14.29)$ & $8(23.53)$ & \multirow[t]{3}{*}{0.493} \\
\hline Atrioventricular block & 39 (70.91) & $15(71.43)$ & $24(70.59)$ & \\
\hline Others & $5(9.09)$ & $3(14.29)$ & $2(5.88)$ & \\
\hline \multicolumn{5}{|c|}{ Disease manifestations (\%) $\left(^{b}\right)$} \\
\hline Syncope & $33(60.00)$ & $13(61.90)$ & $20(58.82)$ & \multirow[t]{4}{*}{0.681} \\
\hline Dizziness & $16(29.09)$ & $7(33.33)$ & $9(26.47)$ & \\
\hline Dyspnoea & $3(5.45)$ & $0(0)$ & $3(8.82)$ & \\
\hline Angina & $3(5.45)$ & $1(4.76)$ & $2(5.88)$ & \\
\hline
\end{tabular}

CM Conventional monitoring; RM Remote monitoring

(a) Concerned to the total initial patients (83)

(b) Indications and manifestations before the PM implant over the remaining sample at the end of the study 


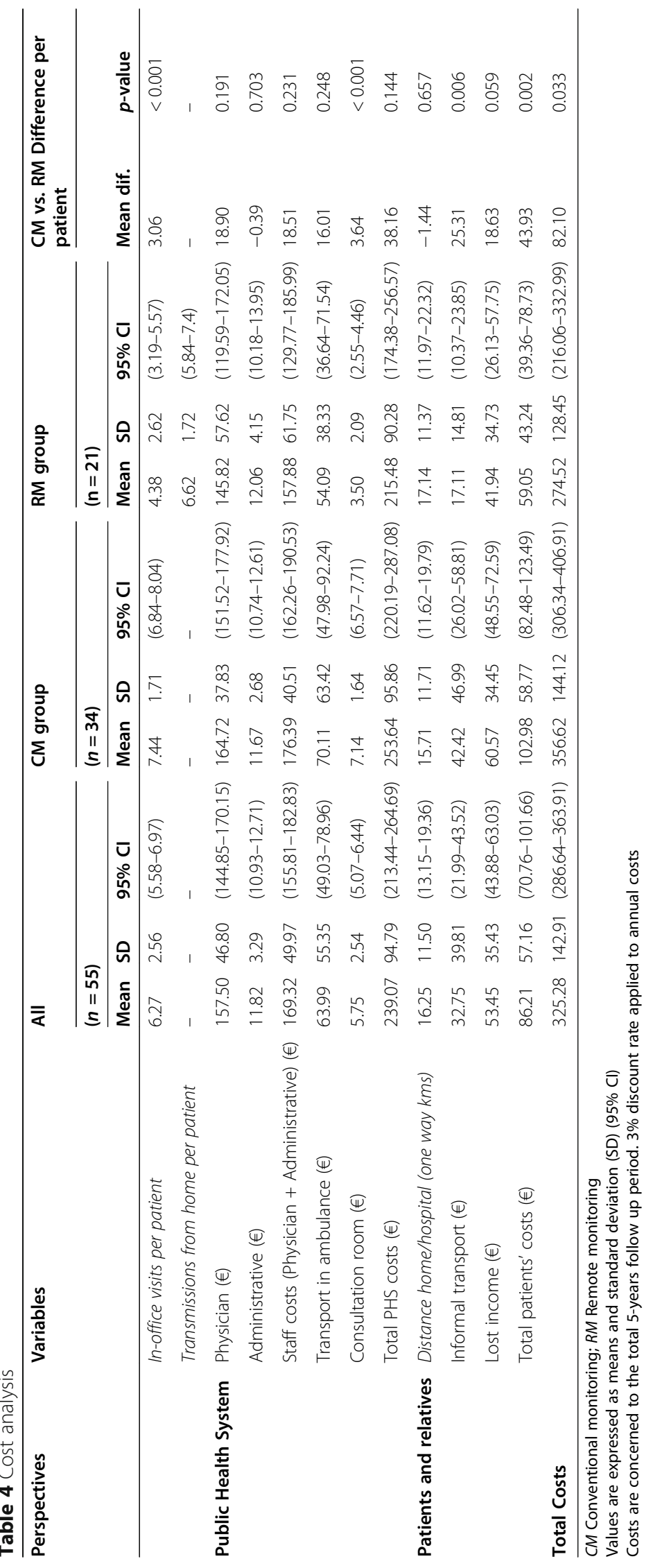


of $81 \pm 7$ years. The female population of the patients comprised of $31 \%$. Significant differences with regards to the assessed clinical characteristics were not observed between the study groups. As shown in Table 3, syncope was the most important disease manifestation (60\%), and 47.27\% of the patients experienced paroxystic Atrial Fibrillation episodes. The atrioventricular block was the most common pacing indication (71\%), followed by sick sinus syndrome (20\%).

\section{Attrition}

Owing to non-cardiovascular causes, 22 patients (RM: 8; CM: 14) died, whereas 6 patients (RM: 1; CM: 5) withdrew from the study. The loss of subjects at 5 years did not correlate with the sex $(p=0.910)$, the age of the participants $(p=0.880)$, or the study criteria variable, type of monitoring conducted $(p=0.110)$.

\section{Costs analysis}

After the five-year follow-up period results in Table 4 revealed that total costs per patient were $23.02 \%$ lower for the RM group than the control group (CM), corresponding to a saving of $€ 82.10$ per patient (RM: $€ 274.52 \pm 128.45 ; \mathrm{CM}: € 356.62 \pm 144.12 ; p=0.033)$.

\section{Public health system perspective}

Significant differences between the mean in-hospital visits per patient of CM and RM groups were estimated after the five-year follow-up period. The number of all types of visits (scheduled or not) to the hospital was higher in the CM group $(7.44 \pm 1.71)$ as compared to the RM group $(4.38 \pm 2.62)(p<0.001)$.

Regarding labor costs, nonsignificant differences were recorded for RM group against CM group (RM: $€ 157.88 \pm 61.75 ; \quad$ CM: $€ 176.39 \pm 40.51 ; p=0.231)$. Staff cost differences were nonsignificant regarding physician labor costs (RM: €145.82 \pm 57.62 ; CM: $€ 164.72 \pm 37.83$; $p=0.191)$ and administrative staff costs (RM: $€ 12.06 \pm$
4.15; CM: $€ 11.67 \pm 2.68 ; p=0.703)$. The former revealed that physicians, unlike administrative staff, spent more time per patient in the CM group, representing a mean $€ 18.90$ cost saving per patient.

Lower usage of transport via ambulance was also revealed by the RM group (RM: $€ 54.09 \pm 38.33$; CM: $€ 70.11 \pm 63.42 ; p=0.248)$. Consultation room costs were also lower in the RM group $(p<0.001)$.

In total, the RM group exhibited a cost saving of 15.04\% per patient from the PHS perspective without statistical significance (RM: $€ 215.48 \pm 90.28 ; \quad C M$ : $€ 253.64 \pm 95.86 ; p=0.144)$.

\section{Patients' perspective}

Although no statistical significance in terms of distance from home to hospital $(p=0.657)$ was found between $\mathrm{RM}$ and $\mathrm{CM}$ groups (one-way trip was lower in CM group $15.71 \pm 11.71 \mathrm{~km}$ than in the RM group $17.14 \pm$ $11.37 \mathrm{~km}$ ), results showed a significant reduction of travel cost for patients in RM group $(€ 17.11 \pm 14.81)$ in comparison to CM group $(€ 42.42 \pm 46.49) \quad(p=0.006)$. Results also portrayed cost saving in the RM group as compared to CM group in terms of income loss of patients and caregivers in every in-office visit (RM: $€ 41.94 \pm 34.73 ; \mathrm{CM}: 60.57 \pm 34.45 ; p=0.059$ ). Overall, from the patients' perspective, RM implied a cost saving of $42.66 \%$ (RM: $€ 59.05 \pm 43.24 ; \mathrm{CM}$ : $€ 102.98 \pm 58.77$; $p=0.002)$.

\section{Cost-utility analysis}

As shown in Table 5, statistically nonsignificant differences were revealed between groups alongside the fiveyear follow-up period.

At the time of enrolment in the study, the overall mean EQ-5D questionnaire of health-related quality of life scores in utilities showed better for patients in the $\mathrm{CM}$ group (EQ5DM00 $=0.72$ ) in comparison to RM group $(\mathrm{EQ} 5 \mathrm{DM} 00=0.70)$. After the first 12 -months

Table 5 Utility values, quality-adjusted life years (QALYS), and cost per patient along the five-year study period

\begin{tabular}{|c|c|c|c|c|c|c|c|c|c|c|c|}
\hline \multirow[t]{2}{*}{ Variables } & \multicolumn{3}{|l|}{ All } & \multicolumn{3}{|c|}{ Conventional Monitoring group } & \multicolumn{3}{|c|}{ Remote Monitoring group } & \multicolumn{2}{|c|}{ Difference per patient } \\
\hline & $\mathrm{n}$ & Mean & SD & $\mathrm{n}$ & Mean & SD & $\mathbf{n}$ & Mean & SD & Mean dif. & $p$-value \\
\hline EQ5 DM00 & 55 & 0.71 & 0.36 & 34 & 0.72 & 0.36 & 21 & 0.70 & 0.38 & 0.02 & 0.795 \\
\hline EQ5 DM12 & 55 & 0.85 & 0.32 & 34 & 0.82 & 0.37 & 21 & 0.90 & 0.19 & -0.08 & 0.301 \\
\hline EQ5 DM60 & 55 & 0.73 & 0.37 & 34 & 0.77 & 0.36 & 21 & 0.68 & 0.39 & 0.09 & 0.363 \\
\hline QALYM60 & 55 & 3.48 & 1.47 & 34 & 3.58 & 1.45 & 21 & 3.31 & 1.52 & 0.27 & 0.515 \\
\hline Cost/QALYM60 (€) & 55 & 195.64 & 515.73 & 34 & 177.08 & 357.90 & 21 & 225.69 & 710.80 & -48.61 & 0.773 \\
\hline Cost/patient $(€)$ & 55 & 325.28 & 142.91 & 34 & 356.62 & 144.12 & 21 & 274.53 & 128.45 & 82.10 & 0.033 \\
\hline ICER & - & - & - & - & - & - & - & - & - & 301.16 & - \\
\hline
\end{tabular}

EQ-5D M12 EuroQoL five-dimensional questionnaire after 12 months; EQ-5D M60 EuroQoL five-dimensional questionnaire after 5 years; QALYM60 quality adjusted life years after 5 years; ICER incremental cost-effectiveness ratio (ICER), calculated as the difference in the expected cost per patient ( $€$ ) divided by the difference in the QALY produced by the two interventions (CM and RM)

$3 \%$ discount rate applied to annual costs and QALYs 


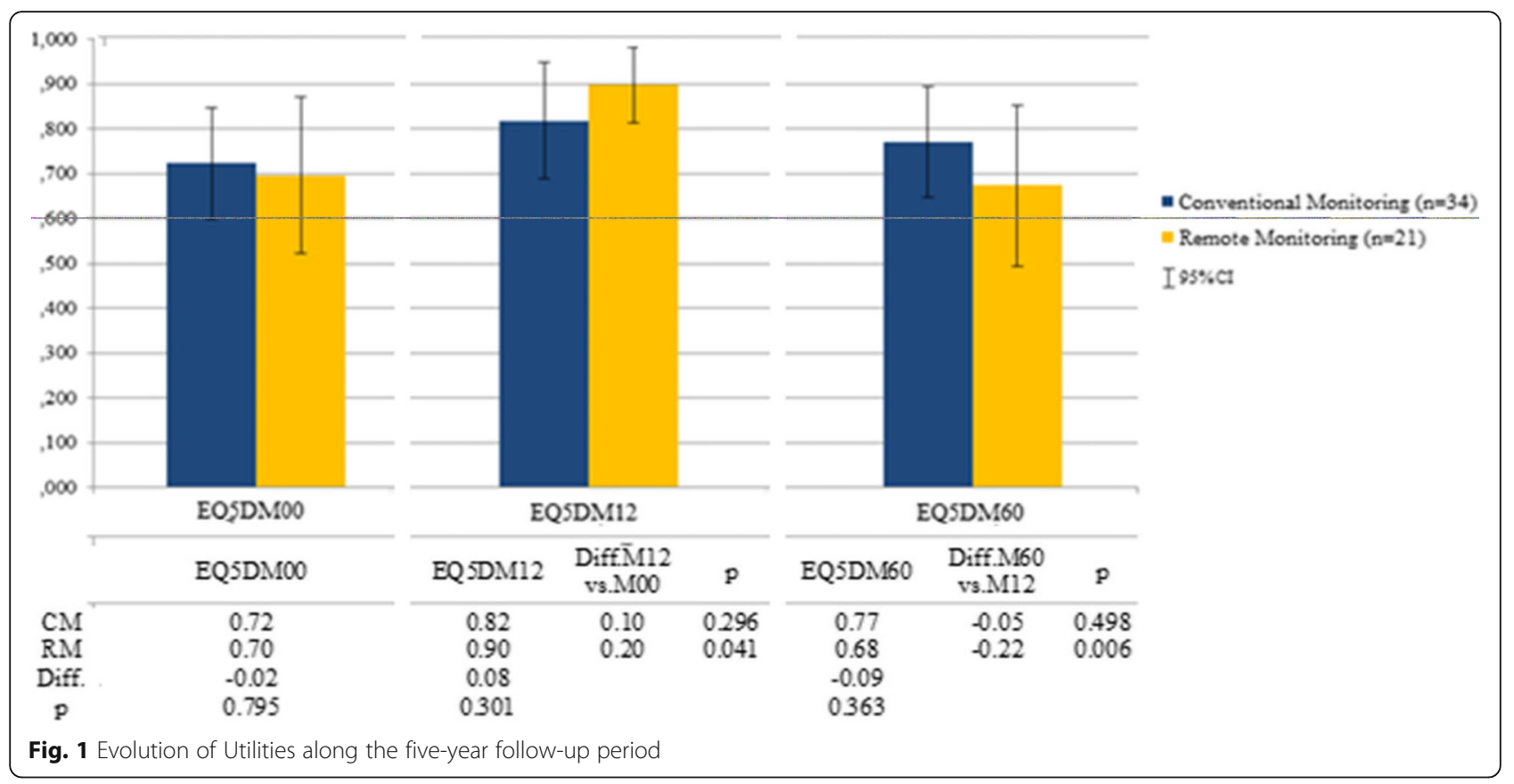

follow-up period, figures became better in the RM group $($ EQ5DM12 $=0.90)$ than in the CM group $(E Q 5 D M 12=$ 0.82). However, at the end of the study, after 5 years months of follow-up, the reduction was evident in the overall mean scores for the RM group (EQ5DM60 = 0.68 ) than the CM group (EQ5DM60 = 0.77). The functional capacity scores were discreetly maintained or slightly declined at 5 years after implantation. Evolution of EQ-5D utilities along the study was depicted in Fig. 1.

Costs/QALYs obtained at 5 years follow up by the RM group $(€ 225.69)$ were higher than the $\mathrm{CM}$ group $(€ 177.08)$, although this data was nonsignificance statistically $(p=0.773)$. Patients belonging to the CM group manifested a slightly better QALY at the end of the study (3.58) than the RM group (3.31). Regarding that, the RM group reported an $€ 82.10$ cost-saving per patient $(p=0.033)$, the ICER of CM in comparison to RM became positive (€301.16) as a measure of costeffectiveness of RM in contrast to CM (Table 5).

\section{Primary model robustness analysis}

The results of the robustness test in Table 6 were in accordance with the data obtained in the previous sections. Statistical analysis confirmed the overall costs per patient in RM group was significantly lower than the CM

Table 6 Cost analysis-robustness test

\begin{tabular}{|c|c|c|c|c|c|c|c|c|c|c|c|c|}
\hline \multirow[t]{3}{*}{ Perspectives } & \multirow[t]{3}{*}{ Variables } & \multirow{2}{*}{\multicolumn{3}{|c|}{$\begin{array}{l}\text { All } \\
(n=10,000)\end{array}$}} & \multirow{2}{*}{\multicolumn{3}{|c|}{$\begin{array}{l}\text { CM group } \\
(n=5000)\end{array}$}} & \multirow{2}{*}{\multicolumn{3}{|c|}{$\begin{array}{l}\text { RM group } \\
(n=5000)\end{array}$}} & \multirow{2}{*}{\multicolumn{2}{|c|}{$\begin{array}{l}\text { CM vs. RM } \\
\text { Difference per } \\
\text { patient }\end{array}$}} \\
\hline & & & & & & & & & & & & \\
\hline & & Mean & SD & $95 \% \mathrm{Cl}$ & Mean & SD & $95 \% \mathrm{Cl}$ & Mean & SD & $95 \% \mathrm{Cl}$ & Mean dif. & $p$-value \\
\hline \multirow{6}{*}{$\begin{array}{l}\text { Public Health } \\
\text { System }\end{array}$} & Physician $(€)$ & 206.44 & 130.58 & $(203.88-209)$ & 207.96 & 160.31 & $(203.52-212.41)$ & 204.92 & 91.68 & $(202.37-207.46)$ & 3.05 & 0.244 \\
\hline & Administrative $(€)$ & 15.76 & 9.67 & $(15.57-15.95)$ & 14.74 & 11.36 & $(14.42-15.05)$ & 16.78 & 7.47 & $(16.57-16.99)$ & -2.04 & $<0.001$ \\
\hline & $\begin{array}{l}\text { Staff costs (Physician } \\
+ \text { Administrative) }(€)\end{array}$ & 222.20 & 140.13 & (219.45-224.95) & 222.70 & 171.67 & (217.94-227.46) & 221.70 & 99.03 & $(218.95-224.44)$ & 1.00 & 0.720 \\
\hline & $\begin{array}{l}\text { Transport in } \\
\text { ambulance }(€)\end{array}$ & 65.90 & 88.92 & $(64.16-67.64)$ & 70.24 & 88.88 & $(67.77-72.7)$ & 61.56 & 88.75 & $(59.1-64.02)$ & 1.78 & $<0.001$ \\
\hline & Consultation room $(€)$ & 7.06 & 5.67 & $(6.95-7.17)$ & 9.02 & 6.95 & $(8.82-9.21)$ & 5.10 & 2.87 & $(5.02-5.18)$ & 3.91 & $<0.001$ \\
\hline & Total PHS costs $(€)$ & 295.16 & 171.38 & $(291.8-298.52)$ & 301.95 & 201.34 & $(296.37-307.53)$ & 288.36 & 134.59 & (284.63-292.09) & 13.59 & $<0.001$ \\
\hline \multirow{3}{*}{$\begin{array}{l}\text { Patients and } \\
\text { relatives }\end{array}$} & Informal transport $(€)$ & 47.86 & 54.14 & $(46.8-48.92)$ & 60.64 & 69.11 & $(58.72-62.55)$ & 35.08 & 27.56 & $(34.31-35.84)$ & 25.56 & $<0.001$ \\
\hline & Lost income $(€)$ & 68.74 & 88.61 & $(67.01-70.48)$ & 76.01 & 103.28 & $(73.14-78.87)$ & 61.48 & 70.25 & $(59.53-63.43)$ & 14.53 & $<0.001$ \\
\hline & Total patients' costs $(€)$ & 116.60 & 125.85 & $(114.13-119.07)$ & 136.64 & 153.12 & $(132.4-140.89)$ & 96.56 & 86.20 & (94.17-98.95) & 40.09 & $<0.001$ \\
\hline Total Costs & & 411.76 & 266.17 & (406.54-416.97) & 438.60 & 324.29 & $(429.6-447.59)$ & 384.92 & 187.35 & (379.72-390.11) & 53.68 & $<0.001$ \\
\hline
\end{tabular}

CM Conventional monitoring; RM Remote monitoring

Values are expressed as means and standard deviation (SD) $(95 \% \mathrm{Cl})$ 
Table 7 Cost-utility analysis-robustness test

\begin{tabular}{|c|c|c|c|c|c|c|c|c|c|c|c|}
\hline \multirow[t]{3}{*}{ Variables } & \multirow{2}{*}{\multicolumn{3}{|c|}{$\frac{\text { All }}{(n=10,000)}$}} & \multirow{2}{*}{\multicolumn{3}{|c|}{$\begin{array}{l}\text { Conventional Monitoring (CM) group } \\
(n=5000)\end{array}$}} & \multirow{2}{*}{\multicolumn{3}{|c|}{$\frac{\text { Remote Monitoring (RM) group }}{(n=5000)}$}} & \multirow{2}{*}{\multicolumn{2}{|c|}{$\begin{array}{l}\text { Difference per } \\
\text { patient }\end{array}$}} \\
\hline & & & & & & & & & & & \\
\hline & $\mathrm{n}$ & Mean & SD & $\mathbf{n}$ & Mean & SD & $n$ & Mean & SD & Mean dif. & $p$-value \\
\hline EQ5 DM12 & 10,000 & 0.87 & 0.82 & 5000 & 0.81 & 0.73 & 5000 & 0.93 & 0.90 & -0.12 & $<0.001$ \\
\hline EQ5 DM60 & 10,000 & 0.72 & 0.61 & 5000 & 0.74 & 0.66 & 5000 & 0.69 & 0.55 & 0.06 & $<0.001$ \\
\hline QALYM60 & 10,000 & 3.43 & 2.34 & 5000 & 3.48 & 2.48 & 5000 & 3.38 & 2.19 & 0.10 & 0.022 \\
\hline Cost/QalyM60 (€) & 10,000 & 215.58 & 543.95 & 5000 & 238.73 & 721.12 & 5000 & 192.43 & 265.94 & 46.30 & $<0.001$ \\
\hline Cost/patient (€) & 10,000 & & & 5000 & 438.60 & 324.29 & 5000 & 384.92 & 187.35 & 53.68 & $<0.001$ \\
\hline ICER & - & - & - & - & - & - & - & - & - & 501.48 & - \\
\hline
\end{tabular}

group, corresponding to a $€ 53.68$ cost saving per patient (RM: $€ 384.92 \pm 187.35$; CM: $€ 438.60 \pm 324.29 ; p<0.001$ ). Significant statistical difference was, however, lacking in the labor costs between RM and CM groups (RM: $€ 221.70 \pm 99.03 ; \mathrm{CM}: € 222.70 \pm 171.67 ; p=0.720)$ as a consequence of the effect of physician labor costs (RM: $€ 204.92 \pm 91.68$; CM: $€ 207.96 \pm 160.31 ; p=0.244)$ and a contradictory effect of administrative staff costs (RM: $€ 16.78 \pm 7.47$; CM: $€ 14.74 \pm 11.36 ; p<0.001)$. Transportation by ambulance, as well as consultation room costs, was lower in the RM group. Therefore, the RM group saved a cost of $4.50 \%$ per patient from the PHS perspective (RM: €288.36 \pm 134.59 ; CM: $€ 301.95 \pm 201.34 ; \mathrm{p}<$ 0.001). Moreover, from patients' perspective also a significant cost saving of RM group was confirmed by the robustness analysis (RM: €96.56 \pm 86.20 ; CM: $€ 136.64 \pm$ 153.12; $\mathrm{p}<0.001$ ), as a consequence of a significant difference in travel cost in RM group as well as costssaving in the RM group in comparison to CM group with respect to income loss of older adults patients and caregivers in every in-office visit.

A positive ICER of CM in comparison to RM (€501.48) affirmed by the cost-utility robustness analysis (Table 7) opined that RM remained a cost-utility alternative in comparison to CM. As in thse primary model, slightly better QALY figures for patients in the CM group (CM: $3.48 \pm 2.48$; RM: $3.38 \pm 2.19 ; p=0.022$ ) were compensated by a cost per patient reduction in the RM group. Moreover, unlike the primary model, Costs/ QALYs obtained by the RM group ( $€ 192.43)$ were significantly $(p<0.001)$ lower than the CM group $(€ 238.73)$, as computed by statistical analysis.

\section{Discussion}

\section{Main findings}

After the five-year follow-up period, cost differences found between RM and CM groups became irrelevant but significant, reporting an $€ 82.10$ cost-saving per older adults patient in the RM group $(p=0.033)$ in the total 5years follow up period. At the end of the study, the CM group showed a better QALY (3.57 vs. 3.30). This result was confirmed by the robustness test. A lower cost per QALY ratio in the RM group (€192.43 vs. €238.73) was also observed. Subsequently, a positive incremental costeffectiveness ratio (ICER) of CM in comparison to RM was found (€301.16).

The mean number of scheduled and unscheduled inhospital visits per patient was reduced by $41.52 \%$ for the RM group, in line with existing research [14, 27, 41, 42]. These outcomes reinforced the results obtained in the 12-months PONIENTE study [30] that showed a reduction of in-hospital visits by $26.89 \%$. Moreover, more recent research [11] confirmed this finding after evaluating a reduction of $79.20 \%$ in the number of in-office visits for 445 patients with PMs and Implantable Cardioverter Defibrillator (unlike our study that only focuses on patients with PMs) followed-up during more than 24 months through RM plus remote interrogations every 6 months. This reduction incurred a significant cost saving of $44.88 \%$ from the patients' perspective, diminishing travel cost for the older adults as well as the level of income loss of patients and caregivers in the RM group.

However, after a five-year follow-up period, this reduction of in-hospital visits failed to display a significant impact on the costs from the PHS perspective, with a cost saving of $16.13 \%$ per patient ( $€ 215.48$ vs. $€ 256.92$; $p=$ 0.112 ). Although a significant reduction in costs from the PHS perspective of $57.64 \%$ in the RM group ( $p<$ 0.001 ) was reported in our 12-months PONIENTE study [29]. This finding was in accordance with the previous studies $[5,10,25,27,43-45]$. After 5 years, the management costs of patients under RM seemed to be unbalanced by the incremental burdens of following up automatic wireless remote notifications by physicians and administrative staff. More recent pacemakers technology is presented as opportunities to allow constant patient "big data" collection, to optimize the outcomes of patients. Henceforth, for future research on remote monitoring, this should be taken into consideration. Thus, as recently suggested, including higher survival ratios in comparison to periodic in-hospital evaluations may be achieved through more frequent (even daily) RM 
transmissions [46]. However, higher efforts must still be made by the clinicians to enable a more efficient practice. With the aim to prioritize clinical decisions and interventions as well as to reduce practitioners' burdens automatized RM data triage through artificial intelligence methods [46] may be implemented.

Although the 12-months PONIENTE study showed an increment in QALYs (+ 0.09) among older patients with PMs under RM as compared to those under CM, our results recorded a higher QALYs decrease $(-0.20)$ for the RM group after the five-year follow-up period. On the contrary, a negative effect on the patients' quality of life was not published by other studies, although for shorter follow-up periods (maximum 24 months) [25, 47, 48] even by using other questionnaires (i.e., SF-36 questionnaire) [10]. These results may indicate a different evolution of utilities in patients under RM for a longer period. Published reports in the literature revealed long-term undesirable effects on the quality of life of patients with pacemakers implantation under conventional monitoring [49]. This previous study observed a moderate increase in the SF-36 general scores for patients with bradycardia pacemaker implantation for the first 24 months postimplantation, which was followed by a gradual decline over time. Physical reasons were the causes of this gradual decline, unlike mental scores, as a consequence of noncardiovascular comorbid diseases usual among geriatric patients. Thus, persistent increase in mental scores drawn from emotional problems and social dysfunctions reflected improved well-being after PM implantation [49]. According to that, some of the major RM benefits from patients' perspectives drawn from the reduction of their in-hospital visits may not be appreciated in the long term in comparison to CM. Moreover, this indicated the need for better patient education regarding the purpose and benefits of RM, its usability, and safety [16], contrary to the findings in short-terms remote monitoring studies [25]. This leads us to the wide debate around social acceptance of telehealth. For shorter follow-up periods, some research does state that a well-structured tele-medical centre available $24 \mathrm{~h}$ a day to act promptly according to the individual patient's risk profile in addition to educational activities [50], as well as continuous 'remote' contact with patients sending clinical reports [11], contribute to balance patients' acceptance. Other studies have found that patients may prefer an in-hospital consultation to establish a diagnosis or to plan their treatment [19]. In the long term this situation may be assimilated to the follow-up of patients with PM. However, to our knowledge, this is the first study where the EQ-5D questionnaire has been used to assess the HRQoL in older patients with PMs under RM for a long-term follow-up period of 5 years. Thus, QALYs obtained could not be compared with those in previous papers on the RM of users with PMs.
Regarding both, PHS and older patients' perspective, cost-utility analysis confirmed that after a 5-years follow-up period, slightly better QALY figures for patients in the CM group may be compensated by a cost per patient reduction in the RM group, assessing in $€ 301.16$ the ICER of CM in comparison to RM.

\section{Limitations}

Although no statistically significant differences were found between both groups in baseline variables assessed (Table 3), the first methodological limitation lies in the fact that it is a non-randomized study where the type of monitoring was recommended by older patients together with the physicians, according to the patients' characteristics. However, no effect of other essential variables on the outcomes was found by the propensity score matching, conducted to explore the variables influencing the election of the type of monitoring $[6,30]$. In any case, greater external validity seems to be achieved as the assignment form used fits the daily practice, and probably the outcomes will be closer to those expected in the real world [51, 52]. Furthermore, the basal characteristics studied were very similar to those reported in the Spanish Pacemaker Registry [53], which supported its generalization. Secondly, it is an open trial where the type of monitoring for every patient was known by both the patients and physicians. This might indulge in biasness in the patients' and physicians' behavior. Third, other decives more than pacemakers, like implantable cardioverter defibrillators (ICD) or cardiac resynchronization therapy devices (CRT), have not been inserted in this study. Then, our results can not be extended to complete devices patients. Fourth, differences of sample size among groups, as well as the limited population size drawn from a single center with a limited number of implants per year, might contribute to the reduction in the statistical power of the study. The similarity of the results with existing research $[3,5,8,14,15]$ does not suggest the influence of differences in the size of both groups on our findings. The level of attrition along the five-year follow-up period may also have affected the results. However, the analysis of attrition demonstrated the similarity between participants who left and those who remained in the program for both groups of monitoring. In any case, as far as the loss of subjects is concerned, the methodology followed in this study prevented generalization of the results among nonsurvivors. In the same way, generalization among other European Health Public Systems should be cautious as the sample was concentrated in a single Spanish hospital. Finally, the final cost difference between both groups may be affected by the fact that the CareLink Monitor associated cost was afforded by the supplier 
(Medtronic $\odot$ ), so it was not considered within either the PHS or the patients' costs.

\section{Conclusions}

The PONIENTE trial affirmed, after 5 years of RM of older patients with pacemakers, that it remains a costutility alternative to conventional monitoring in hospitals. However, although significant cost savings were still appreciated from older patients' perspective, PHS management costs differences between both groups seemed to be leveled off. Optimization of the incremental staff burdens of following up automatic remote notifications is presented as a challenge for future studies in RM of older patients with pacemakers.

\section{Abbreviations}

RM: Remote Monitoring; CM: Conventional Monitoring; QALYs: QualityAdjusted Life Years; PHS: Public Health System; PM: Pacemakers; EQ5D: EuroQol-5D; HRQoL: Health-Related Quality of Life; ICER: Incremental Cost-Effectiveness Ratio

\section{Acknowledgements}

We are thankful to the patients and their caregivers who took part in the study and acknowledge the invaluable support of the PONIENTE research team.

\section{Authors' contributions}

Author Contributions: Conceptualization, A.L.-V., C.L-C, and D.C.-M.; methodology, C.L-C., R.L.-L., A.L.-V., S.-P. and D.C.-M.; formal analysis, C.L-C. investigation, A.L.-V., S.-P. and D.C.-M.; resources, A.L.-V., R.J.B-M and E.R-M.; data curation, A.L.-V., E.R-M.; writing-original draft preparation, R.J.B-M.; writing -review and editing, R.L.-L., A.L.-V., E.R-M., S.-P., C.L-C., and D.C.-M.; visualization, A.L.-V., and D.C.-M.; supervision, S.-P.; A.L.-V., and D.C.-M.; project administration, A.L.-V. and C.L-C.; funding acquisition, A.L.-V., C.L-C., R.J.B-M., S.-P. and D.C.-M. All authors have read and approved the final manuscript.

\section{Funding}

This study has been funded by Instituto de Salud Carlos III through the project "No. PI17/02056" (Co-funded by European Regional Development Fund/European Social Fund "A way to make Europe"/"Investing in your future") and by the General Secretariat for Research, Development and Innovation, Regional Government of Andalusia (Spain), with Project Reference No. Pl/0256/2017, under the research call "Development and Innovation Projects in the Field of Biomedicine and Health Sciences". The funders had no role in the study design, data collection and analysis, decision to publish, or preparation of the manuscript. The authors performed all research related activities independently.

\section{Availability of data and materials}

The datasets used and/or analyzed during the present study are available from the corresponding author on reasonable request.

\section{Ethics approval and consent to participate}

Precepts of ethics and research marked by the Declaration of Helsink concerning medical research were followed to conduct the trial. The protocol was approved by the Regional Health Research Ethical Committee (CEIC-AL: 53/2012), and all patients signed the informed consent before their inclusion in the study.

\section{Consent for publication}

Not applicable.

\section{Competing interests}

The authors declare that they have no competing interests.

\section{Author details}

${ }^{1}$ Management Unit, Hospital de Poniente, El Ejido, Almeria, Spain. ${ }^{2}$ Social Involvement of Critical and Emergency Medicine, CTS-609 Research Group, Hospital de Poniente, El Ejido, s/n, 04700 Almeria, Spain. ${ }^{3}$ Health Services Research Unit, FISABIO-PUBLIC HEALTH, Valencia, Spain. ${ }^{4}$ Department of Communication Studies, University Carlos III of Madrid, Madrid, Spain. ${ }^{5}$ Health Sciences CTS-451 Research Group, University of Almería, Almería, Spain. ${ }^{6}$ Pacemaker Unit, Intensive Care Unit, Hospital de Poniente, El Ejido, Almería, Spain. ${ }^{7}$ Department of Nursing Science, Physiotherapy and Medicine, Hum498 Research Team, Health Research Centre, University of Almería, Almería, Spain. ${ }^{8}$ Nursing Department, University of Murcia, Murcia, Spain.

Received: 18 June 2020 Accepted: 9 November 2020 Published online: 16 November 2020

\section{References}

1. Wilkoff BL, Auricchio A, Brugada J, Cowie M, Ellenbogen KA, Gillis AM, Hayes DL, Howlett JG, Kautzner J, Love CJ, Morgan JM, Priori SG, Reynolds DW, Schoenfeld MH, Vardas PE, Heart Rhythm Society (HRS); European Heart Rhythm Association (EHRA); American College of Cardiology (ACC); American Heart Association (AHA); European Society of Cardiology (ESC); Heart Failure Association of ESC (HFA); Heart Failure Society of America (HFSA). HRS/EHRA Expert Consensus on the Monitoring of Cardiovascular Implantable Electronic Devices (CIEDs): description of techniques, indications, personnel, frequency and ethical considerations: developed in partnership with the Heart Rhythm Society (HRS) and the European Heart Rhythm Association (EHRA); and in collaboration with the American College of Cardiology (ACC), the American Heart Association (AHA), the European Society of Cardiology (ESC), the Heart Failure Association of ESC (HFA), and the Heart Failure Society of America (HFSA). Endorsed by the Heart Rhythm Society, the European Heart Rhythm Association (a registered branch of the ESC), the American College of Cardiology, the American Heart Association. Europace. 2008 Jun;10(6):707-25.

2. Cronin E, Varma N. Remote monitoring of cardiovascular implanted electronic devices: a paradigm shift for the 21st century. Expert Rev Med Devices. 2012;9(4):367-76.

3. Mabo P, Victor F, Bazin P, Ahres S, Babuty D, Da Costa A, Binet D, Dauber J C.t. A randomized trial of long-term remote monitoring of pacemaker recipients (The COMPAS trial). European Heart Journal 2012; 33: 1105-1111.

4. Amala A, Turner T, Gretton M, Baksh A, Cleland J. A systematic review of telemonitoring for the management of heart failure. European Journal of Heart Failure. 2003:5:583-90.

5. Folino AF, Breda R, Calzavara P, Migliore F, Iliceto S, Buja G. In-home controls of pacemakers in debilitated elderly patients. Geriatrics and gerontology international. 2012;12:30-5.

6. López-Villegas A, Catalán-Matamoros D, Robles-Musso E, Peiró S. Comparative effectiveness of remote monitoring of people with cardiac Pacemaker versus conventional: Quality of life at the 6 months. Revista Española de Salud Pública. 2015;89(2):149-58.

7. López-Villegas A, Catalán-Matamoros D, Robles-Musso E, Peiró S. Effectiveness of Pacemaker Tele-Monitoring on Quality of Life, Functional Capacity, Event Detection and Workload. The PONIENTE trial. Geriatrics and Gerontology International. 2016;16(11):1188-95.

8. Ricci RP, Morichelli L, Santini M. Home monitoring remote control of pacemaker and implantable cardioverter defibrillator patients in clinical practice: impact on medical management and health-care resource utilization. Europace. 2008;10:164-70.

9. Guedon-Moreau L, Lacroix D, Sadoul N, Clementy J, Kouakam C, Hermida JS, Aliot E, Boursier M, Bizeau O, Kacet S, ECOST trial Investigators. A randomized study of remote follow-up of implantable cardioverter defibrillators: safety and efficacy report of the ECOST trial. European Heart Journal. 2013;34:605-14.

10. Halimi F, Clémenty J, Attuel P, Dessenne X, Amara W, on behalf of the OEDIPE trial Investigators. Optimized post-operative surveillance of permanent pacemakers by home monitoring: the OEDIPE trial. Europace. 2008;10:1392-9.

11. García-Fernández FJ, Osca Asensi J, Romero R, Fernández Lozano I, Larrazabal JM, Martínez Ferrer J, Ortiz R, Pombo M, Tornés FJ, Moradi Kolbolandi M. Safety and efficiency of a common and simplified protocol for pacemaker and defibrillator surveillance based on remote monitoring 
only: a long-term randomized trial (RM-ALONE). European Heart Journal. 2019;40(23):1837-46

12. Barlow J, Bayer S, Curry R. Implementing complex innovations in fluid multistakeholder environments: Experiences of "telecare". Technovation. 2006;26: 396-406.

13. Christensen J. The emergence and unfolding of telemonitoring practices in different healthcare organizations. International journal of environmental research and public health. 2018;15(1):61.

14. Zanaboni P, Landolina M, Marzegalli M, Lunati M, Perego GB, Guenzati G, Curnis A, Valsecchi S, Borghetti F, Borghi G, Masella C. Cost-utility analysis of the EVOLVO study on remote monitoring for heart failure patients with implantable defibrillators: randomized controlled trial. Journal of medical Internet research. 2013;15(5):106.

15. Halimi F, Cantu F. Remote monitoring for active cardiovascular implantable electronic devices: a European survey. Europace. 2010;12:1778-80.

16. Health Quality Ontario. Remote monitoring of implantable cardioverterdefibrillators, cardiac resynchronization therapy, and permanent pacemakers: a health technology assessment. Ont Health Technol Assess Ser [Internet]. 2018 Oct;18 (7):1-199. Available from: http://www.hqontario ca/evidenceto-improve-care/journal-ontario-health-technologyassessmentseries.

17. Haugaa KH, Potpara TS, Boveda S, Deharo JC, Chen J, Dobreanu D, Sciarrafia E. Patients' knowledge and attitudes regarding living with implantable electronic devices: results of a multicentre, multinational patient survey conducted by the European Heart Rhythm Association. Ep Europace. 2017; 20(2):386-91.

18. Somat A. Acceptabilité, acceptabilité sociale des systèmes technologiques: ingénierie de la notion d'usage. Grenoble: Conférence des sciences de l'éducation, Université Pierre-Mendès-France; 2008.

19. Poder TG, Bellemare CA, Bédard SK, Lemieux R. Social acceptance and population confidence in telehealth in Quebec. BMC Health Services Research. 2015;15:72

20. Winkelmayer WC, Cohen DJ, Berger ML, Neumann PJ. Comparing cost-utility analyses in cardiovascular medicine. In: Weintraub WS, editor. Cardiovascular Health Care Economics. Totowa: Humana Press; 2003. p. 329-56.

21. Burri H, Sticherling C, Wright D, Makino K, Smala A, Tilden D. Costconsequence analysis of daily continuous remote monitoring of implantable cardiac defibrillator and resynchronization devices in the UK. Europace. 2013;15(11):1601-8.

22. Urquhart AC, Antoniotti NM, Berg RL. Telemedicine - an efficient and costeffective approach in parathyroid surgery. Laryngoscope. 2011;121(7):14225.

23. Capucci A, De Simone A, Luzi M, Calvi V, Stabile G, D'Onofrio A, Maffei S, Leoni L, Morani G, Sangiuolo R, Amellone C, Checchinato C, Ammendola E, Buja G. Economic impact of remote monitoring after implantable defibrillators implantation in heart failure patients: an analysis from the EFFE CT study. Europace. 2017 Sep 1;19(9):1493-9.

24. Dario C, Delise P, Gubian L, Saccavini C, Brandolino G, Mancin S. Large controlled observational study on remote monitoring of pacemakers and implantable cardiac defibrillators: a clinical, economic, and organizational evaluation. Interact J Med Res. 2016;5(1):4.

25. Raatikainen MJ, Uusimaa P, van Ginneken MM, Janssen JP, Linnaluoto M. Remote monitoring of implantable cardioverter defibrillator patients: a safe, time-saving, and cost-effective means for follow-up. Europace. 2008;10(10): $1145-51$.

26. Hofmann $\mathrm{R}$, Voller $\mathrm{H}$, Nagels $\mathrm{K}$, et al. First outline and baseline data of a randomized, controlled multicenter trial to evaluate the health economic impact of home telemonitoring in chronic heart failure - CardioBBEAT. Trials. 2015;16:343.

27. Perl S, Stiegler P, Rotman B, Prenner G, Lercher P, Anelli-Monti M, Sereinigg M, Riegelnik V, Kvas E, Kos C, Heinzel FR, Tscheliessnigg KH, Pieske B. Socioeconomic effects and cost saving potential of remote patient monitoring (SAVE-HM trial). International Journal of Cardiology. 2013;169:402-7.

28. López-Villegas A, Catalán-Matamoros D, Martín-Saborido C, Villegas Tripiana I, Robles-Musso E. A Systematic Review of Economic Evaluations of Pacemaker Telemonitoring Systems. Revista Española de Cardiología. 2016; 69(2):125-33.

29. Lopez-Villegas A, Catalan-Matamoros D, Peiro S, Lappegard K, Lopez-Liria R. Cost-utility analysis of telemonitoring versus conventional hospital-based follow-up of patients with pacemakers. The NORDLAND randomized clinical trial. PLOS ONE. 2020;15(1):e0226188.
30. Lopez-Villegas A, Catalan-Matamoros D, Robles-Musso E, Bautista-Mesa R, Peiro S. Cost-utility analysis on telemonitoring of users with pacemakers: The PONIENTE study. Journal of Telemedicine and Telecare. 2019;25(4):204-12.

31. Medtronic. How the CareLink Network Works [monograph on the Internet]. 2014 http://www.medtronic.com/patients/sudden-cardiac-arrest/living-with/ carelink/how-it-works/index.htm. Accessed 18 Jun 2020.

32. Radio Taxi-Almería. Calcular precio del servicio [monograph on the Internet]. 2018. http://www.radiotaxialmeria.es/tarifastaxi/calculador?metodo= km\&destino $=\& \mathrm{~km}=41$ \&horasespera $=0 \& o p=C$ alcular+precio\&form_build_id $=$ form-bb7b2d74fd39ec52558a348b1e0f99d1\&form_id=_tarifastaxi_calcular_ form. Accessed 18 Jun 2020

33. ALSA Hacemos tu viaje más fácil. Compra y horarios [monograph on the Internet]. http://www.alsa.es/compra-y-horarios/regionales/andalucia/ ? searchType=short\&zone=5. Accessed 18 Jun 2020.

34. Agencia Estatal de la Administración Tributaria. Asignaciones para gastos de locomoción [monograph on the Internet]. 2018. https:/www. agenciatributaria.es/AEAT.internet/Inicio/Ayuda/Manuales_Folletos_y_ Videos/Manuales_de_ayuda_a_la_presentacion/Ejercicio_2016/_Ayuda_ Modelo_100/7_Cumplimentacion_IRPF_1/17_2_Rendimientos_del_ trabajo_personal/7_2_1_Rendimientos_integros/7_2_1_2_Dietas_y_ gastos_de_viaje/Asignaciones_para_gastos_de_locomocion/Asignaciones_ para_gastos_de_locomocion.html. Accessed 18 Jun 2020.

35. Ministerio de Empleo y Seguridad Social. Retribuciones [monograph on the Internet]. 2013. http://www.empleo.gob.es/es/portada/serviciohogar/ preguntas-frecuentes/retribuciones/. Accessed 18 Jun 2020.

36. Badia X, Roset M, Montserrat S, Herdman M, Segura A. La versión española del EuroQol: descripción y aplicaciones. Medicina Clínica. 1999;112(Supl 1): 79-86.

37. EuroQol Group. EuroQol . A new facility for the measurement of healthrelated quality of life. Health Policy. 1990;16:199-208.

38. Drummond MF, Sculpher MJ, Torrance GW, O'Brien BJ, Stoddart GL. Methods for the Economic Evaluation of Health Care Programmes. 3rd ed. New York, NY: Oxford University Press; 2005.

39. Gold MR, Siegel JE, Russell LB, Weinstein MC. Cost-Effectiveness in Health and Medicine. New York, NY: Oxford University Press; 1996.

40. Altawalbeh SM, Alshogran OY, Smith KJ. Cost-Utility Analysis of Apixaban versus Warfarin in Atrial Fibrillation Patients with Chronic Kidney Disease. Value in Health. 2018;21(12):1365-72.

41. Crossley GH, Boyle A, Vitense A, Chang Y. Mead RH for the CONNECT Investigators, The CONNECT (Clinical Evaluation of Remote Notification to Reduce Time to Clinical Decision) Trial: The value of wireless remote monitoring with automatic clinician alerts. Journal of the American College of Cardiology. 2011;57:1182-9.

42. Lopez-Villegas A, Catalan-Matamoros D, Lopez-Liria R, Enebakk T, Thunhaug H, Lappegård KT. Health-related quality of life on tele-monitoring for users with pacemakers 6 months after implant: the NORDLAND study, a randomized trial. BMC Geriatr. 2018;18(1):223.

43. Folino A, Breda R, Calzavara P, Borghetti F, Comisso J, lliceto S, Buja G. Remote follow-up of pacemakers in a selected population of debilitated elderly patients. Europace. 2013;15(3):382-7.

44. Morgan JM, Kitt S, Gill J, McComb JM, Ng GA, Raftery J, Roderick P, Seed A, Williams SG, Witte KK, Wright DJ, Harris S, Cowie MR. Remote management of heart failure using implantable electronic devices. European Heart Journal. 2017;38(30):2352-60.

45. Boriani G, Da Costa A, Quesada A, Ricci RP, Favale S, Boscolo G, Clementy N, Amori V, Mangoni di S Stefano L, Burri H; MORE-CARE Study Investigators, Effects of remote monitoring on clinical outcomes and use of healthcare resources in heart failure patients with biventricular defibrillators: results of the MORE-CARE multicentre randomized controlled trial. European Journal of Heart Failure. 2017;19 (3):416-425.

46. Freeman JV, Saxon L. Remote Monitoring and Outcomes in Pacemaker and Defibrillator Patients. Big Data Saving Lives? Journal of the American College of Cardiology. 2015 Jun 23;65(24):2611-3.

47. Zabel M, Müller-Riemenschneider F, Christoph Geller FJ, Brachmann J, Kühlkamp V, Dissmann R, Reinhold T, Roll S, Lüthje L, Bode F, Eckardt L, Willich SN, investigators MONITOR-ICD. Rationale and design of the MONITOR-ICD study: A randomized comparison of economic and clinical effects of automatic remote monitoring versus control in patients with Implantable Cardioverter Defibrillators. American Heart Journal. 2014;168(4):430-7.

48. Neyt M, Stroobandt S, Obyn C, Camberlin C, Devriese S, De Laet C, Van Brabandt $\mathrm{H}$. Cost-effectiveness of cardiac resynchronisation therapy for 
patients with moderate-to-severe heart failure: a lifetime Markov model. BMJ Open. 2011;1(2):e000276.

49. Udo EO, van Hemel NM, Zuithoff NP, Nijboer H, Taks W, Doevendans PA, Moons KG. Long term quality-of-life in patients with bradycardia pacemaker implantation. International Journal of Cardiology 2013 Oct 3;168(3):21592163. doi: https://doi.org/10.1016/j.ijcard.2013.01.253. Epub 2013 Feb 28. PMID: 23453871

50. Koehler F, Koehler K, Deckwart O, Prescher S, Wegscheider K, Kirwan BA, Winkler S, Vettorazzi E, Bruch L, Oeff M, Zugck C, Doerr G, Naegele H, Störk S, Butter C, Sechtem U, Angermann C, Gola G, Prondzinsky R, Edelmann F, Spethmann S, Schellong SM, Schulze PC, Bauersachs J, Wellge B, Schoebel C, Tajsic M, Dreger H, Anker SD, Stangl K. Efficacy of telemedical interventional management in patients with heart failure (TIM-HF2): a randomised, controlled, parallel-group, unmasked trial. Lancet. 2018 Sep 22; 392(10152): 1047-57.

51. Chang S, Davidson PM, Newton PJ, Macdonald P, Carrington MJ, Marwick TH, Horowitz JD, Krum H, Reid CM, Chan YK, Scuffham PA, Sibbritt D, Stewart S, Investigators WHICH. Composite outcome measures in a pragmatic clinical trial of chronic heart failure management: A comparative assessment. International Jorunal of Cardiology. 2015 Apr 15;185:62-8. https://doi.org/10.1016/j.jicard.2015.03.071. Epub 2015 Mar 5 25791092

52. Pocock SJ, Gersh BJ. Do current clinical trials meet society's needs?: a critical review of recent evidence. J Am College Cardiology. 2014;64:1615-28.

53. Cano Pérez O, Pombo Jiménez M, Lorente Carreño D, Chimeno García J. Spanish Pacemaker Registry. 16th Official Report of the Spanish Society of Cardiology Working Group on Cardiac Pacing (2018). Revista Española de Cardiología. 2019;72(11):944-53.

\section{Publisher's Note}

Springer Nature remains neutral with regard to jurisdictional claims in published maps and institutional affiliations.

Ready to submit your research? Choose BMC and benefit from:

- fast, convenient online submission

- thorough peer review by experienced researchers in your field

- rapid publication on acceptance

- support for research data, including large and complex data types

- gold Open Access which fosters wider collaboration and increased citations

- maximum visibility for your research: over $100 \mathrm{M}$ website views per year

At $\mathrm{BMC}$, research is always in progress.

Learn more biomedcentral.com/submissions 